\title{
Staphylococcal enterotoxin B and $\alpha$-toxin induce the apoptosis of ECV304 cells via similar mechanisms
}

\author{
FENG-LING YU ${ }^{1,2^{*}}$, TING-TING LIU ${ }^{1,2^{*}}$, XIANG ZHU ${ }^{1,2}$, WENG-XUAN YANG ${ }^{1,2}$, TAO ZHANG ${ }^{1,2}$, \\ NA LIN ${ }^{1,2}$, YONG LIU ${ }^{1,2}$, CONG-SEN LIU ${ }^{1,2}$, JIU JIANG ${ }^{2,3}$ and JUN-CHANG GUAN ${ }^{1,2}$ \\ ${ }^{1}$ Anhui Key Laboratory of Infection and Immunity; ${ }^{2}$ Department of Microbiology, Bengbu Medical College, Bengbu, \\ Anhui 233030, P.R. China; ${ }^{3}$ Department of Biology, Drexel University College of Arts and Sciences, \\ Philadelphia, PA 19104, USA
}

Received January 30, 2013; Accepted June 13, 2013

DOI: $10.3892 / \mathrm{mmr} .2013 .1550$

\begin{abstract}
Staphylococcal enterotoxin B (SEB) and $\alpha$-toxin produced by Staphylococcus aureus (S. aureus) are important in the pathogenesis of diseases. In the present study, we investigated the effects of SEB and $\alpha$-toxin on ECV304 cells. It was identified that both SEB and $\alpha$-toxin were capable of inducing the apoptosis of ECV304 cells in a dose- and time-dependent manner. In addition, SEB and $\alpha$-toxin were able to induce the expression of TNF- $\alpha$ and the activation of caspase- 3 and -8 in the ECV304 cells. The inhibition of TNF- $\alpha$ (with its neutralizing antibody) and caspase- 3 and -8 [with the corresponding inhibitory peptides; $\mathrm{z}-\mathrm{N}$-acetyl-Asp-Glu-ValAsp-aminomethyl-coumarin (DEVD)-fluoromethyl ketone (FMK) for inhibition of caspase-3 and z-N-acetyl-Ile-Glu-ThrAsp (IETD)-FMK) for inhibition of caspase-8] significantly decreased the rates of cell apoptosis induced by SEB and $\alpha$-toxin, but was not able to completely block the induced cell apoptosis. These data suggest that SEB and $\alpha$-toxin induce ECV304 cell apoptosis via a similar mechanism, which is partially mediated by the extrinsic death pathway involving TNF- $\alpha$ and caspase- 8 . These results provide insights into the synergistic pathogenicity of SEB and $\alpha$-toxin during $S$. aureus infection.
\end{abstract}

\section{Introduction}

Staphylococcus aureus (S. aureus) is one of the most common bacterial infections worldwide, and is a common pathogen that is encountered clinically by obstetricians, gynecologists and

Correspondence to: Professor Jun-Chang Guan, Anhui Key Laboratory of Infection and Immunity and Department of Microbiology, Bengbu Medical College, 2600 Donghai Road, Bengbu, Anhui 233030, P.R. China

E-mail: gjc-2003@sohu.com

*Contributed equally

Key words: apoptosis, $\alpha$-toxin, staphylococcal enterotoxin b, Staphylococcus aureus neonatologists (1-3). It is carried by $25-35 \%$ of the population as residential bacterial flora, which may cause a wide range of diseases (including arthritis, osteomyelitis, dermatitis and mastitis), as well as bacteremia, abscesses, toxemia and sepsis. These suppurative infections are associated with tissue destruction and cell death (4). Multiple virulence factors are required for $S$. aureus to induce apoptosis in infected cells, among which staphylococcal enterotoxin B (SEB) and $\alpha$-toxin are important. $\alpha$-toxin, a $34-\mathrm{kDa}$ pore-forming protein, is essential for the modulation of $S$. aureus-induced cytotoxicity in Jurkat T lymphocytes, human peripheral blood lymphocytes and monocytes (5). In addition, $\alpha$-toxin is capable of inducing the apoptosis of epithelial $(6)$ and endothelial $(7,8)$ cells. SEB is not only an exotoxin associated with fatal toxic shock syndrome (9), but also a superantigen with the capacity to strongly activate oligoclonal populations of $\mathrm{T}$ lymphocytes, which express antigen receptors with homologous $\beta$ chain variable regions (V $\beta$ families) (10). A number of studies have demonstrated that SEB activates the pathways controlling the process of apoptosis in a variety of cell types $(11,12)$. As SEB and $\alpha$-toxin are simultaneously produced by $S$. aureus and are involved in disease pathogenesis, it is necessary to investigate whether SEB and $\alpha$-toxin are able to induce the apoptosis of the same cells.

Apoptosis, or programmed cell death, is primarily mediated by a family of intracellular cysteine proteases, termed caspases (13). Caspases are synthesized as inactive proenzymes and are proteolytically processed to form an active complex. Caspases may be divided into initiator and effector caspases, according to their structure and order. Initiator caspases, including caspase- 8 and -9 , exert regulatory roles. Upon binding to signal transducing molecules, they activate downstream effector caspases, such as caspase-3, which cleave various cellular substrates, thereby inducing the death of the cell $(14,15)$. The activation of caspases is achieved via two principal signaling pathways, namely the extrinsic and intrinsic death pathways (14). The extrinsic death pathway involves the ligation of death receptors (CD95/Fas/APO-1 and TNF receptor-1), resulting in the recruitment of the adapter molecule, Fas-activated death domain (FADD), and pro-caspase- 8 into a death-inducing signaling complex. By contrast, the intrinsic death pathway is initiated at the mito- 
chondrion by the release of cytochrome $c$, a process that is inhibited by anti-apoptotic proteins of the Bcl-2 family. When released, cytosolic cytochrome $c$ binds to dATP, and apoptosis-activating factor-1 binds to pro-caspase-9, to form the apoptosome. Upon the formation of this death-inducing signaling complex, pro-caspase- 8 and -9 are autoproteolytically processed, respectively, resulting in the activation of downstream caspases. In this study, we utilized ECV304 cells, which exhibit certain endothelial characteristics and are advantageous for the study of receptor pharmacology and cytochemistry (16). The cells were used to investigate whether SEB and $\alpha$-toxin were able to induce the apoptosis of ECV304 cells, and whether this occurred via similar mechanisms.

\section{Materials and methods}

Reagents. SEB and $\alpha$-toxin were purchased from Sigma-Aldrich (St. Louis, MO, USA). Polyclonal anti-human TNF- $\alpha$ was purchased from PeproTech, Inc. (Rocky Hill, NJ, USA). Caspase-3 inhibitory peptide [z-N-acetyl-Asp-Glu-ValAsp-aminomethyl-coumarin (DEVD)-fluoromethyl ketone (FMK)], caspase-8 inhibitory peptide [z-N-acetyl-Ile-Glu-ThrAsp (IETD)-FMK], the Caspase-3 Colorimetric Assay kit and the Caspase-8 Colorimetric Assay kit were purchased from BioVision (Mountain View, CA, USA). The human TNF- $\alpha$ Legend Max $^{\mathrm{TM}}$ ELISA kit was obtained from BioLegend, Inc. (San Diego, CA, USA), and the Annexin V-FITC staining kit was purchased from Pharmingen (Heidelberg, Germany).

Cell lines and culture. ECV304 cells (Cell Lines Service, Gmbh, Eppelheim, Germany) were maintained in RPMI-1640 medium (Gibco-BRL, Carlsbad, CA, USA) with $2 \mathrm{mM}$ L-glutamine, adjusted to contain $1.5 \mathrm{mg} / \mathrm{ml}$ sodium bicarbonate, and supplemented with $0.1 \mathrm{mg} / \mathrm{ml}$ heparin, $10 \%$ heat-inactivated fetal bovine serum (FBS), $50 \mu \mathrm{g} / \mathrm{ml}$ streptomycin and $50 \mu \mathrm{g} / \mathrm{ml}$ penicillin at $37^{\circ} \mathrm{C}$ in a humidified atmosphere with $5 \% \mathrm{CO}_{2}$. Assays were performed in RPMI-1640 medium that was not supplemented with $10 \%$ FBS. In certain experiments, the RPMI-1640 medium was supplemented with various inhibitors, antibodies and/or different concentrations of SEB or $\alpha$-toxin.

Treatment of cultured cells with SEB or $\alpha$-toxin, antibodies and various inhibitors. Cultured cells were counted and plated at a density of $1 \times 10^{5} / \mathrm{ml}$ in 6-well tissue culture plates. When the cells had adhered to the plates and the medium was changed to serum-free RPMI-1640 medium, different concentrations of SEB or $\alpha$-toxin were added to the cells for $8 \mathrm{~h}$. Soluble culture supernatants and cell pellets were collected following centrifugation at $400 \mathrm{x} \mathrm{g}$ for $10 \mathrm{~min}$. The level of TNF- $\alpha$ in the culture supernatants was measured using the ELISA kit, according to the manufacturer's instructions. The levels of apoptosis and caspase activity were measured in the cell pellets. When antibody or caspase inhibitors were used, anti-human TNF- $\alpha$, z-DEVD-FMK or z-IETD-FMK was added to the cultured cells, resulting in final concentrations of $20 \mu \mathrm{g} / 1,2 \mathrm{mM}$ and $2 \mathrm{mM}$, respectively. Cell pellets were also collected in order to detect apoptosis by flow cytometry. Cells cultured without SEB or $\alpha$-toxin were used as controls in all assays.
Detection of apoptosis by flow cytometric analysis. To monitor the apoptosis-related changes in the plasma membrane, phosphatidylserine was detected on the surface of the plasma membrane using annexin V, and the membrane permeability was assessed using propidium iodide (PI) (17), according to the instructions provided by the manufacturer of the Annexin V staining kit. Briefly, $1 \times 10^{5} / \mathrm{ml}$ cells were exposed to medium alone (that did not contain FBS) or various inhibitors, antibodies, and/or different concentrations of SEB or $\alpha$-toxin. The cells were then washed and re-suspended in $0.1 \mathrm{ml}$ staining solution [ $2 \%$ annexin V-FITC and 2\% PI-phycoerythrin (PE), by volume, in HEPES buffer], and incubated for $15 \mathrm{~min}$ in the dark at room temperature. The cells were then analyzed by flow cytometry on a fluorescence-activated cell sorting system (FACSCalibur, Becton Dickinson, Heidelberg, Germany) using CellQuest analysis software (BD Biosciences). For each determination, a minimum of 50,000 cells were analyzed. Live cells were not stained with PI or annexin V. Early apoptotic cells were defined as those stained with annexin V, but not with PI, and late apoptotic or necrotic cells were defined as those stained with both reagents.

Colorimetric determination of caspase-3 and - 8 activity. The activity of the caspases was determined using Caspase Colorimetric Assay kits according to the manufacturer's instructions. Briefly, cell lysates were incubated for $2 \mathrm{~h}$ at $37^{\circ} \mathrm{C}$ with $5 \mu \mathrm{l}$ of the $4 \mathrm{mM}$ substrates [DEVD- $p$-nitroanilide ( $p$ NA) for caspase-3, or IETD- $p$ NA for caspase-8] in a 50- $\mu 1$ reaction buffer, containing $50 \mathrm{mM}$ HEPES (pH 7.4), $100 \mathrm{mM}$ $\mathrm{NaCl}, 10 \%$ sucrose, $0.1 \%$ CHAPS and $10 \mathrm{mM}$ DTT. Based on the chromophore $p$ NA following cleavage from the labeled substrate (DEVD- $p$ NA or IETD- $p$ NA), the $p$ NA light emission was quantified using a spectrophotometer at $405 \mathrm{~nm}$. The comparison between the absorbance of $p \mathrm{NA}$ in an apoptotic sample and in an uninduced control enabled the determination of the fold-increase in caspase activity.

Statistical analysis. The results are presented as the mean \pm SEM. To assess the significance of differences within experiments, a Tukey b test in a one-way analysis of variance (ANOVA) was used. $\mathrm{P}<0.05$ was considered to indicate a statistically significant difference.

\section{Results}

Induction of apoptosis in ECV304 cells exposed to SEB or $\alpha$-toxin. Flow cytometry analysis of FITC-annexin V-labeled cells stained with PI enabled host cells in the early and late stages of apoptosis to be distinguished. Following the incubation of the ECV304 cells with different concentrations of SEB or $\alpha$-toxin for $8 \mathrm{~h}$, SEB (Fig. 1A) and $\alpha$-toxin (Fig. 1B) were demonstrated to induce the apoptosis of ECV304 cells in a dose-dependent manner. The level of apoptotic cells reached a peak at $5 \mu \mathrm{g} / \mathrm{ml}$ SEB and $30 \mathrm{ng} / \mathrm{ml} \alpha$-toxin; hence, these concentrations were then utilized when investigating the level of apoptosis over $8 \mathrm{~h}$ in the incubated ECV304 cells. When the ECV304 cells were incubated with $5 \mu \mathrm{g} / \mathrm{ml} \mathrm{SEB}$ or $30 \mathrm{ng} / \mathrm{ml} \alpha$-toxin for different lengths of time, the level of apoptotic cells represented a statistically significant $(\mathrm{P}<0.05)$ time-dependent increase (Fig. 2). 
A

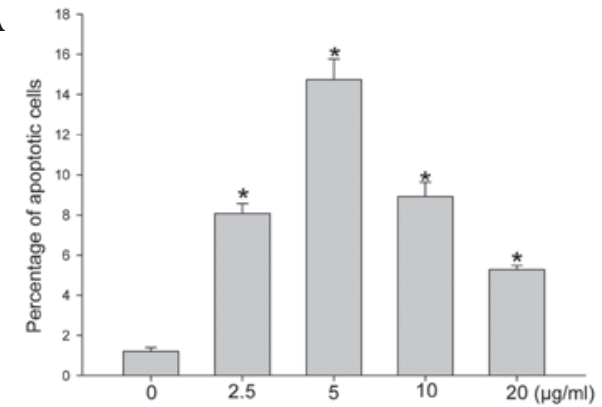

B

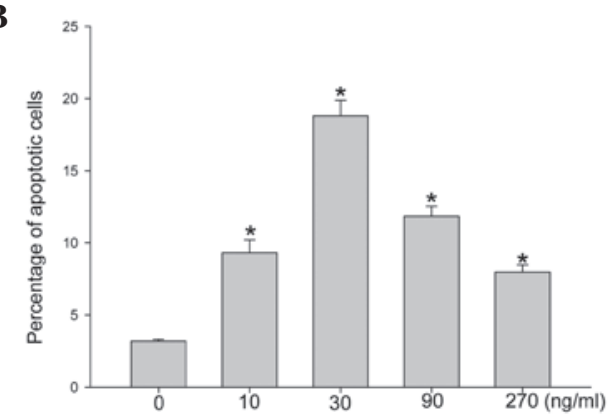

Figure 1. Staphylococcal enterotoxin B (SEB) and $\alpha$-toxin induce the apoptosis of ECV304 cells in a dose-dependent manner. ECV304 cells were exposed to the indicated concentrations of (A) SEB and (B) $\alpha$-toxin for $8 \mathrm{~h}$. The percentage of apoptotic cells was calculated with data from the triplicates of five experiments. Error bars represent the standard deviations. ${ }^{*} \mathrm{P}<0.01$ compared with the controls [(A) $0 \mu \mathrm{g} / \mathrm{ml} \mathrm{SEB}$ or (B) $0 \mathrm{ng} / \mathrm{ml} \alpha$-toxin].

A

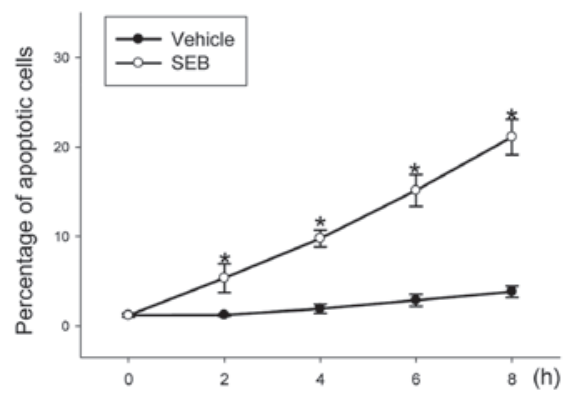

B

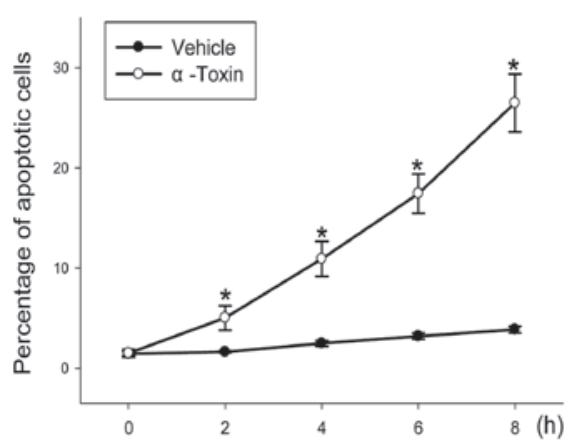

Figure 2. Staphylococcal enterotoxin B (SEB) and $\alpha$-toxin induce the apoptosis of ECV304 cells in a time-dependent manner. ECV304 cells were exposed to (A) $5 \mu \mathrm{g} / \mathrm{ml} \mathrm{SEB}$ or (B) $30 \mathrm{ng} / \mathrm{ml} \alpha$-toxin for the indicated times. The percentage of apoptotic cells was calculated with data from the triplicates of five experiments. Error bars represent the standard deviations. ${ }^{\text {"P }}<0.01$ compared with the controls [(A) $0 \mu \mathrm{g} / \mathrm{ml} \mathrm{SEB}$ or (B) $0 \mathrm{ng} / \mathrm{ml} \alpha$-toxin] at the same timepoint.

Cell apoptosis induced by SEB or $\alpha$-toxin is partially mediated by $T N F-\alpha$. Apoptosis is achieved via two principal signaling pathways, the extrinsic and intrinsic death pathways $(14,15)$.
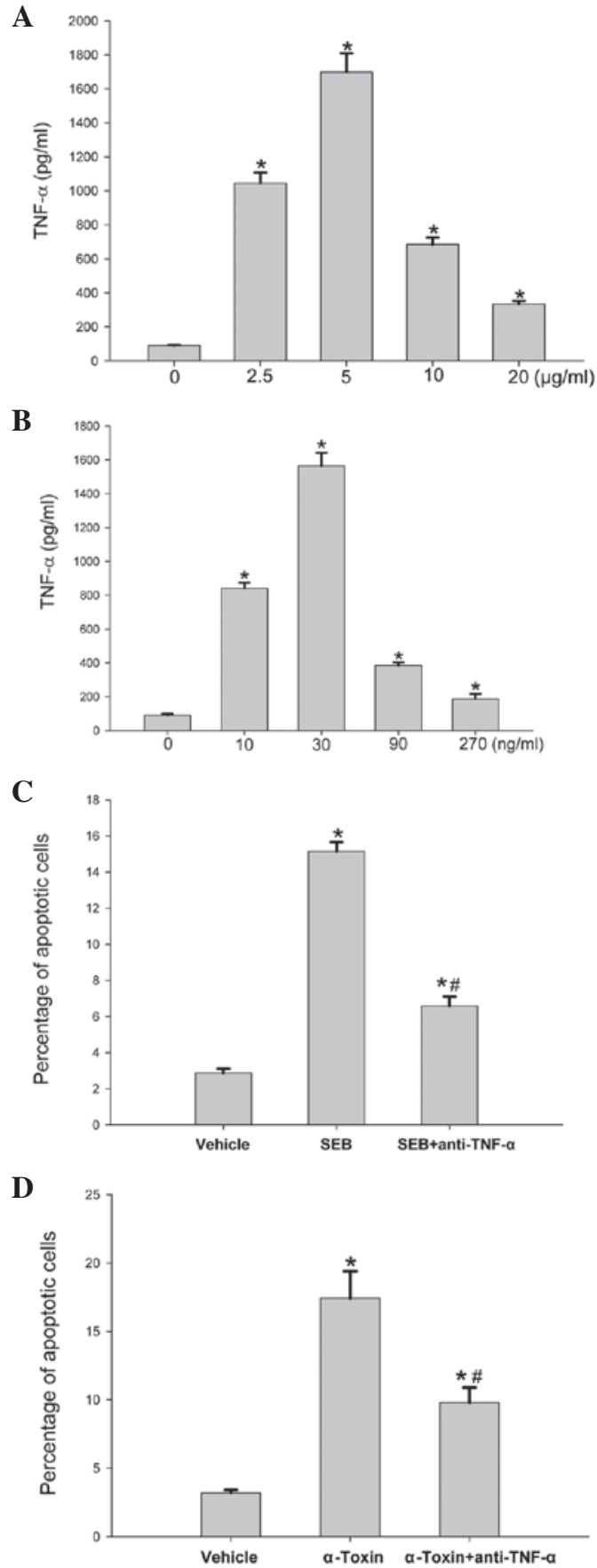

Figure 3. Staphylococcal enterotoxin B (SEB) and $\alpha$-toxin-induced cell death is partially mediated by TNF- $\alpha$. (A and B) Following $8 \mathrm{~h}$ of incubation with the indicated concentration of (A) SEB or (B) $\alpha$-toxin, the level of TNF- $\alpha$ production was detected in the obtained supernatants of the ECV304 cells by enzyme-linked immunosorbent assay (ELISA). (C and D) The incubated ECV304 cells were treated with $5 \mu \mathrm{g} / \mathrm{ml} \mathrm{SEB} \mathrm{(C)} \mathrm{or} 30 \mathrm{ng} / \mathrm{ml} \alpha$-toxin (D) in the absence or presence of anti-TNF- $\alpha$ antibody for $8 \mathrm{~h}$. The rates of induced cell apoptosis were determined by flow cytometry. Data were calculated from the triplicates of five experiments. Error bars represent the standard deviations. " $\mathrm{P}<0.01$ compared with the controls; ${ }^{\#} \mathrm{P}<0.01$ compared with $\mathrm{SEB}$ or $\alpha$-toxin alone.

It was predicted that TNF- $\alpha$ may be involved in the induction of cell death. To test the hypothesis, we measured the level of TNF- $\alpha$ production and the effect of TNF- $\alpha$ antibody on cell apoptosis induced by SEB or $\alpha$-toxin. Following an 8-h incubation of the ECV304 cells with different concentrations of SEB or $\alpha$-toxin, the level of TNF- $\alpha$ production was 
A

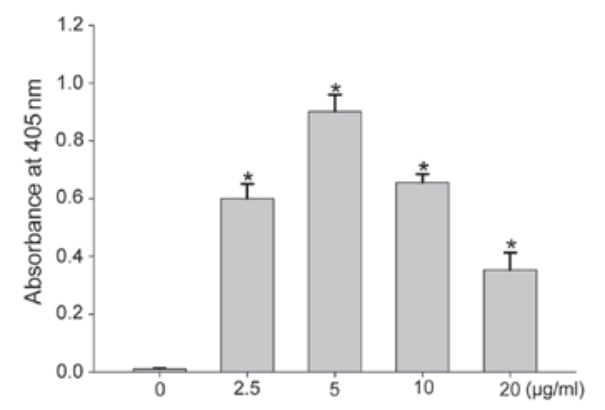

C

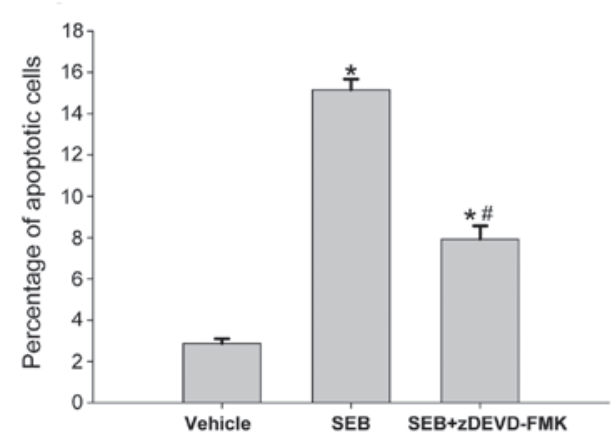

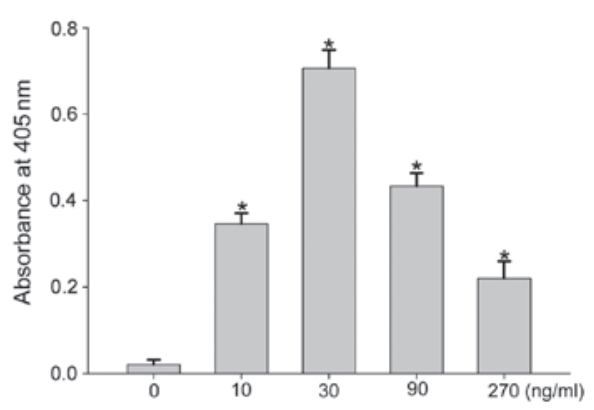

D

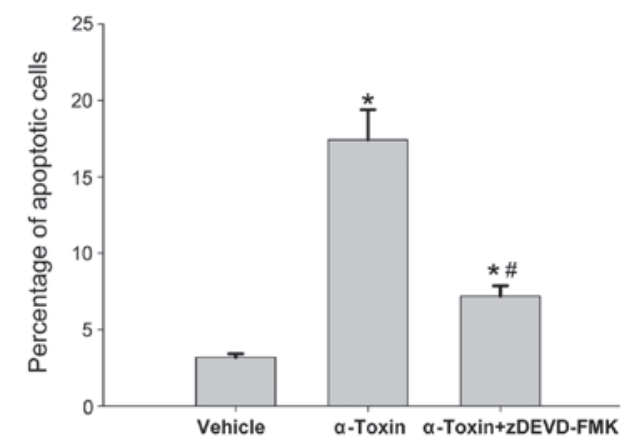

Figure 4. Staphylococcal enterotoxin B (SEB) and $\alpha$-toxin activate caspase-3 in ECV304 cells. (A and B) Following 8 h of incubation with the indicated concentration of (A) SEB or (B) $\alpha$-toxin in the ECV304 cells, caspase-3 activity was investigated in the cell extracts, and was determined by the ability to cleave the fluorogenic substrate, DEVD-pNA, using the Caspase-3 Colorimetric Assay kit. Absorbance at $405 \mathrm{~nm}$ represented the caspase-3 activity. (C and D) The incubated ECV304 cells were treated with (C) $5 \mu \mathrm{g} / \mathrm{ml} \mathrm{SEB}$ or (D) $30 \mathrm{ng} / \mathrm{ml} \alpha$-toxin in the absence or presence of an inhibitor of caspase-3 [z-N-acetyl-Asp-Glu-Val-Asp-aminomethyl-coumarin (DEVD)-fluoromethyl ketone (FMK)] for $8 \mathrm{~h}$. The rates of induced cell apoptosis were determined by flow cytometry. Data were calculated from the triplicates of five experiments. Error bars represent the standard deviations. ${ }^{*} \mathrm{P}<0.01$ compared with the vehicle; ${ }^{\text {"P }}<0.01$ compared with SEB or $\alpha$-toxin alone.

A

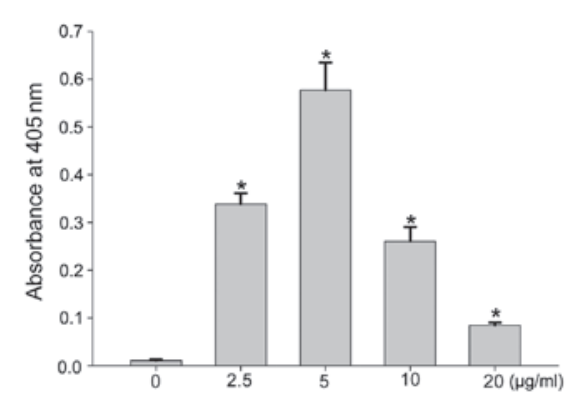

C

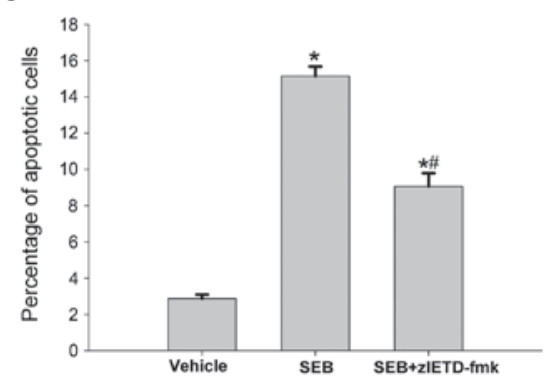

B

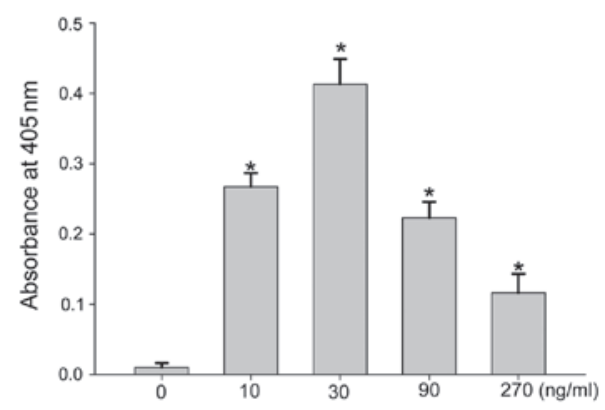

D

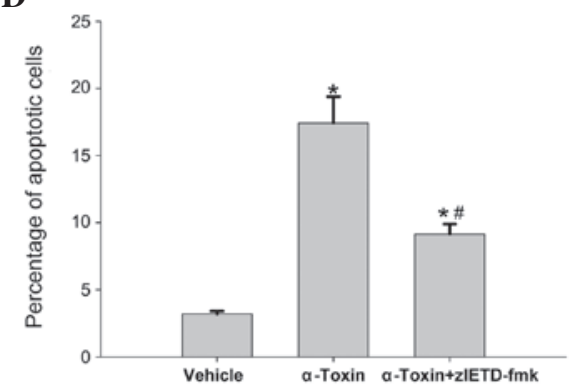

Figure 5. Staphylococcal enterotoxin B (SEB) and $\alpha$-toxin activate caspase- 8 in ECV304 cells. (A and B) Following $8 \mathrm{~h}$ of incubation with the indicated concentration of (A) SEB or (B) $\alpha$-toxin, the caspase- 8 activity in the ECV304 cell extracts was determined by the ability to cleave the fluorogenic substrate, IETD-pNA, using the Caspase- 8 Colorimetric Assay kit. Absorbance at $405 \mathrm{~nm}$ represented the caspase- 8 activity. (C and D) The incubated ECV304 cells were treated with (C) $5 \mu \mathrm{g} / \mathrm{ml} \mathrm{SEB}$ or (D) $30 \mathrm{ng} / \mathrm{ml} \alpha$-toxin in the absence or presence of an inhibitor of caspase-8 [z-N-acetyl-Ile-Glu-Thr-Asp (IETD)-fluoromethyl ketone $(\mathrm{FMK})]$ for $8 \mathrm{~h}$. The rates of induced cell apoptosis were determined by flow cytometry. Data were calculated from the triplicates of five experiments. Error bars represent the standard deviations. " $\mathrm{P}<0.01$ compared with the vehicle; ${ }^{*} \mathrm{P}<0.01$ compared with SEB or $\alpha$-toxin alone. 
significantly higher than that of the control cells (Fig. 3A and B). The addition of an anti-TNF- $\alpha$ antibody to the incubated ECV304 cells prior to the addition of SEB or $\alpha$-toxin significantly decreased the rates of cell apoptosis induced by SEB or $\alpha$-toxin (Fig. 3C and D); however, the rates of apoptosis remained higher than those of the control cells.

SEB and $\alpha$-toxin activate caspase- 3 and -8 in ECV304 cells. Apoptosis is predominantly mediated by activation of the caspase cascade, resulting in the cleavage of several death substrates. To examine the cell death pathway induced by SEB or $\alpha$-toxin in more detail, we incubated ECV304 cells with SEB or $\alpha$-toxin, and analyzed the cell extracts for caspase- 3 and -8 activity, as determined by the ability to cleave DEVD- $p$ NA or IETD- $p$ NA (the labeled substrates), respectively. Following $8 \mathrm{~h}$ of incubation, the addition of SEB and $\alpha$-toxin resulted in a dose-dependent increase in caspase- 3 (Fig. 4A and B) and -8 (Fig. 5A and B) activity in the ECV304 cells. Similar to the rates of apoptotis induced by SEB and $\alpha$-toxin, caspase- 3 and -8 activation also peaked at $5 \mu \mathrm{g} /$ $\mathrm{ml} \mathrm{SEB}$ and $30 \mathrm{ng} / \mathrm{ml} \alpha$-toxin, respectively. Following the addition of caspase-3 inhibitory peptide (z-DEVD-FMK) or caspase- 8 inhibitory peptide (z-IETD-FMK) to the incubated ECV304 cells, prior to the addition of SEB or $\alpha$-toxin, the rates of cell death were significantly decreased compared with those observed with SEB or $\alpha$-toxin alone. However, compared with the control cells (Figs. 4C and D, and 5C and D), the rates of apoptosis remained higher in the cells with z-IETD-FMK and $\mathrm{z}$-DEVD-FMK. These results suggested that the inhibitors exerted a significant inhibitory effect on the subsequent induction of apoptosis and activation of caspase-3/8, which was partially mediated by SEB and $\alpha$-toxin.

\section{Discussion}

S. aureus is a human commensal bacteria and also a predominant cause of community and nosocomial infection $(2,3,18)$. SEB and $\alpha$-toxin produced by $S$. aureus are important in disease pathogenesis. Apoptosis is a major cause of cell death and tissue destruction in S. aureus infection (19). In this study, we identified that SEB and $\alpha$-toxin were able to induce the apoptosis of ECV304 cells in a dose- and time-dependent manner. This is concordant with other studies demonstrating that SEB was capable of inducing the apoptosis of human Jurkat cells (11), and $\alpha$-toxin was able to induce the apoptosis of human peripheral blood lymphocytes, monocytes (5), and epithelial (6) and endothelial $(7,8)$ cells.

As SEB and $\alpha$-toxin induce the apoptosis of ECV304 cells, it may be beneficial to understand the mechanism by which this occurs. Apoptosis is primarily mediated by a family of intracellular cysteine proteases, termed caspases $(13,20)$. Caspase activation is achieved via two principal signaling pathways, the extrinsic and intrinsic death pathways $(14,15)$. In this study, it was revealed that $\alpha$-toxin stimulated the expression of TNF- $\alpha$ in the supernatants of ECV304 cells, which was consistent with a previous study demonstrating that the expression of TNF- $\alpha$ was upregulated in epithelial (6) and peripheral blood mononuclear (21) cells treated by $S$. aureus $\alpha$-toxin. In addition, the removal of TNF- $\alpha$ with a neutralizing antibody significantly decreased $\alpha$-toxin-induced cell death, but did not completely inhibit apoptosis. These findings suggested that TNF- $\alpha$ contributes to $\alpha$-toxin-induced apoptosis through the extrinsic death pathway. In addition, we demonstrated that ECV304 cell apoptosis induced by SEB shared similar mechanisms to apoptosis induced by $\alpha$-toxin. To the best of our knowledge, this is the first study indicating that SEB may partially induce the apoptosis of ECV304 cells through the extrinsic death pathway.

Since SEB and $\alpha$-toxin initiated cell apoptosis by TNF- $\alpha$ binding to the TNF- $\alpha$ receptors in the host, downstream caspase pathways were also investigated. A small number of studies have demonstrated that $S$. aureus and $\alpha$-toxin are able to activate both the effector caspase- 3 and the two key initiator caspases, caspase- 8 and $-9(22,23)$. Concordant with these studies, the results of the present study demonstrated that $\alpha$-toxin induced the activation of caspase- 3 and -8 . In addition, the inhibition of either caspase -3 or -8 by their inhibitors significantly decreased, but did not completely block, the $\alpha$-toxin-induced cell death. The downstream caspase pathways of ECV304 cell apoptosis induced by SEB were also investigated. It was identified that SEB and $\alpha$-toxin had a similar mechanism of inducing the activation of caspase- 3 and caspase-8. These results demonstrated that caspase-8, of the extrinsic death pathway, partially mediates the apoptosis of ECV304 cells induced by SEB and $\alpha$-toxin.

In conclusion, SEB and $\alpha$-toxin induced the apoptosis of ECV304 cells in a dose- and time-dependent manner. TNF- $\alpha$ expression induced by SEB and $\alpha$-toxin contributed to mediating the death of the ECV304 cells, by the activation of caspase-3 and -8 . These results suggested that SEB and $\alpha$-toxin induce ECV304 cell apoptosis via similar mechanisms, partially mediated by the extrinsic death pathway of TNF- $\alpha$ and caspase- 8 . This study has provided insights into the synergistic pathogenicity of SEB and $\alpha$-toxin during $S$. aureus infection.

\section{Acknowledgements}

The authors would like to thank Dr Bai-qing Li, Department of Immunology, Bengbu Medical College (Bengbu, China) for assistance in the FACS analysis. This study was supported by grants from the National Science Foundation of China (grant no. 81070506).

\section{References}

1. Alonzo F 3rd, Kozhaya L, Rawlings SA, et al: CCR5 is a receptor for Staphylococcus aureus leukotoxin ED. Nature 493: 51-55, 2013.

2. Lewis SS, Moehring RW, Anderson DJ, Sexton DJ and Chen LF: Increasing rates of methicillin-resistant Staphylococcus aureus in academic hospitals: a result of active surveillance? Infect Control Hosp Epidemiol 34: 105-106, 2013.

3. Sax H, Posfay-Barbe K, Harbarth S, et al: Control of a cluster of community-associated, methicillin-resistant Staphylococcus aureus in neonatology. J Hosp Infect 63: 93-100, 2006.

4. Alexander EH and Hudson MC: Factors influencing the internalization of Staphylococcus aureus and impacts on the course of infection in humans. Appl Microbiol Biotechnol 56: 361-366, 2001.

5. Essmann F, Bantel H, Totzke G, et al: Staphylococcus aureus alpha-toxin-induced cell death: predominant necrosis despite apoptotic caspase activation. Cell Death Differ 10: 1260-1272, 2003.

6. Liang X and Ji Y: Involvement of alpha5beta1-integrin and TNF-alpha in Staphylococcus aureus alpha-toxin-induced death of epithelial cells. Cell Microbiol 9: 1809-1821, 2007. 
7. Menzies BE and Kourteva I: Staphylococcus aureus $\alpha$-toxin induces apoptosis in endothelial cells. FEMS Immunol Med Microbiol 29: 39-45, 2000.

8. Haslinger-Löffler B, Kahl BC, Grundmeier M, et al: Multiple virulence factors are required for Staphylococcus aureus-induced apoptosis in endothelial cells. Cell Microbiol 7: 1087-1097, 2005.

9. Karauzum H, Chen G, Abaandou L, et al: Synthetic human monoclonal antibodies toward staphylococcal enterotoxin B (SEB) protective against toxic shock syndrome. J Biol Chem 287: 25203-25215, 2012.

10. Bi S, Das R, Zelazowska E, et al: The cellular and molecular immune response of the weanling piglet to staphylococcal enterotoxin B. Exp Biol Med (Maywood) 234: 1305-1315, 2009.

11. Higgs BW, Dileo J, Chang WE, et al: Modeling the effects of a Staphylococcal Enterotoxin B (SEB) on the apoptosis pathway. BMC Microbiol 6: 48, 2006.

12. Kedzierska A, Kaszuba-Zwoińska J, Słodowska-Hajduk Z, et al SEB-induced $\mathrm{T}$ cell apoptosis in atopic patients - correlation to clinical status and skin colonization by Staphylococcus aureus. Arch Immunol Ther Exp (Warsz) 53: 63-70, 2005.

13. Los M, Wesselborg S and Schulze-Osthoff K: The role of caspases in development, immunity, and apoptotic signal transduction: lessons from knockout mice. Immunity 10: 629-639, 1999.

14. Schulze-Osthoff K, Ferrari D, Los M, Wesselborg S and Peter ME: Apoptosis signaling by death receptors. Eur J Biochem 254: 439-459, 1998.

15. Li H and Yuan J: Deciphering the pathways of life and death. Curr Opin Cell Biol 11: 261-266, 1999.

16. Brown J, Reading SJ, Jones S, et al: Critical evaluation of ECV304 as a human endothelial cell model defined by genetic analysis and functional responses: a comparison with the human bladder cancer derived epithelial cell line T24/83. Lab Invest 80 $37-45,2000$
17. Koopman G, Reutelingsperger CP, Kuijten GA, Keehnen RM, Pals ST and Van Oers MH: Annexin V for flow cytometric detection of phosphatidylserine expression on B-cells undergoing apoptosis. Blood 84: 1415-1420, 1994

18. McKinnell JA, Huang SS, Eells SJ, Cui E and Miller LG Quantifying the impact of extranasal testing of body sites for methicillin-resistant Staphylococcus aureus colonization at the time of hospital or intensive care unit admission. Infect Control Hosp Epidemiol 34: 161-170, 2013.

19. Menzies BE and Kourteva I: Internalization of Staphylococcus aureus by endothelial cells induces apoptosis. Infect Immun 66: 5994-5998, 1998.

20. Cohen GM: Caspases: the executioners of apoptosis. Biochem J 326: 1-16, 1997.

21. Haslinger B, Strangfeld K, Peters G, Schulze-Osthoff K and Sinha B: Staphylococcus aureus alpha-toxin induces apoptosis in peripheral blood mononuclear cells: role of endogenous tumor necrosis factor-alpha and the mitochondrial death pathway. Cell Microbiol 5: 729-741, 2003

22. Bantel H, Sinha B, Domschke W, Peters G, Schulze-Osthoff K and Janicke RU: alpha-Toxin is a mediator of Staphylococcus aureus-induced cell death and activates caspases via the intrinsic death pathway independently of death receptor signaling. J Cell Biol 155: 637-647, 2001.

23. Wesson CA, Deringer J, Liou LE, Bayles KW, Bohach GA and Trumble WR: Apoptosis induced by Staphylococcus aureus in epithelial cells utilizes a mechanism involving caspases 8 and 3 . Infect Immun 68: 2998-3001, 2000. 